\title{
Outcome of Probing for Congenital Naso-Lacrimal Duct Obstruction
}

Mozammel Hoq Sharife ${ }^{1^{*}}$ M Jalal Uddin ${ }^{2}$

Mostak Ahmed

'Department of Ophthalmology Chattagram Maa-O-Shishu Hospital Medical College: Agrabad, Chittagong, Bangladesh.

${ }^{2}$ Department of Community Medicine Chattagram Maa-O-Shishu Hospital Medical College Agrabad, Chittagong, Bangladesh.

${ }^{3}$ Department of Ophthalmology Dhaka Medical College, Bangladesh.
*Correspondence to:

\section{Dr. Mozammel Hoque Sharifi}

Assistant Professor of Ophthalmology Chattagramm Maa O Shishu Hospital Medical College Chittagong, Bangladesh

Mobile : +8801911-881547

Email :drmozammelhoque66@gmail.com

http://www.banglajol.info/index.php/CMOSHMCJ

\begin{abstract}
Objective: The study was conducted to evaluate outcome of probing for congenital nasolacrimal duct obstruction. It was an interventional study at a tertiary level hospital of Chittagong. Methods: The study was conducted during April 2009 to March 2013 (04 years). Total 120 eyes of 102 children of 1-3 years age group were probed. Minimum follow up time was 01 year. Results: 110 eyes fully cured, 05 eyes needed re-probing, 03 eyes needed Dacrocystorhinostomy operation (DCR) and 02 cases were dropped out. Male female ratio was $72(60 \%)$ and $48(40 \%)$. Conclusion: Outcome of probing is better among 1-2 years age group than that of 23 years age group. A discussion is made with updated literature review.
\end{abstract}

Key words: Nasolacrimal duct; CNLDO; Probing, Congenital.

\section{INTRODUCTION}

Five percent $(5 \%)$ newborn babies suffer from Congenital Nasolacrimal Duct Obstruction (CNLDO). This is due to mal-development of nasolacrimal drainage system. Obstruction occurs at different levels: commonest site of obstruction is at valve of Hasner. General stenosis of duct may be there. In some cases maldevelopment of punctum and canaliculi have been observed. Congenital absence of valves and other causes were also recorded.

History and clinical examinations are enough for diagnosis of CNLDO.

Conservative management is usually given up to first birth day. Non respondents are considered for probing and DCR. After all GA fitness probing is done. Standard post operative management with antibiotic and analgesics also needed. Probed patient needs follow up according to a schedule. Some patients need re-probing. Non responding patients need DCR operation ${ }^{1}$.

\section{MATERIALS AND METHODS}

\begin{tabular}{|l|l|}
\hline Study title & $\begin{array}{l}\text { Outcome of probing for congenital nasolacrimal } \\
\text { duct obstruction }\end{array}$ \\
\hline Study period & April 2009 to March 2014 (4 years) \\
\hline Study type & Interventional study with probing and DCR \\
\hline Sampling technique & Convenient sampling \\
\hline Sample size & 120 eyes of 102 babies \\
\hline Data collection & Investigator himself \\
\hline Data management & Co investigator \\
\hline Statistical analysis & Z test was used. \\
\hline Ethical implication & Informed written consent was taken from guardians \\
\hline
\end{tabular}




\section{RESULTS}

Total 102 babies. 120 eyes underwent probing. Male - female representation $72(60 \%)$ and $48(40 \%) .97(80 \%)$ cases were of 1 2 year age group and remaining 23(20\%) were of 2-3 year age group. Among 120 cases 115(97\%) cured with probing, 03 $(03 \%)$ cases underwent DCR operation and 02 cases were dropped out. All DCR were done after $3^{\text {rd }}$ birth day when $3^{\text {rd }}$ probing failed.

Table 1 : Outcome of probing of congenital nasolacrimal duct obstruction cases

\begin{tabular}{lccc} 
Age group & Cured & Not cured & Total \\
\hline 1-2 year & $95(100 \%)$ & $00(00 \%)$ & $95(100 \%)$ \\
$2-3$ year & $20(87 \%)$ & $03(13 \%)$ & $23(100 \%)$ \\
Total & $115(97 \%)$ & $03(3 \%)$ & $118(100 \%)$ \\
\hline
\end{tabular}

Source: Hospital records.

\section{DISCUSSION}

Probing was $97 \%$ successful in our study. Only 05 cases needed re-probing. 03 cases who underwent DCR operation had experienced $3^{\text {rd }}$ probing failure. The result is consistent with recent studies in Bangladesh ( $\mathrm{P}=0.059$ ). Study conducted by him in 2013 showed that 104 cases out of 105 cases were cured with probing. Success rate was $99 \%$. Only 01 case underwent DCR operation after failure of $3^{\text {rd }}$ probing ${ }^{2}$. Time of probing is very important. Among 1-2 year age group probing is very rewarding. In our study success rate is $100 \%$. He observed $92 \%$ success rate beyond 01 year after birth ${ }^{3}$. He reported 860 cases of probing in 1985. 06\% cases needed re-probing and only $0.5 \%$ cases needed $3^{\text {rd }}$ time probing ${ }^{4}$.

\section{CONCLUSION}

Probing is very rewarding during 1-2 year age group. A multicenter large scale study may be undertaken before national guideline formulation for management of CNLDO.

\section{DISCLOSURE}

All the authors declare no competing interest

\section{REFERENCES}

1. Kanski J J. Clinical Ophthalmology. $6^{\text {th }}$ edition. 156

2. Alam N. Outcome of probing. Outcome of probing for CNLDO. JOSB. 2013; 40(1).

3. Rabb R M. Success rate of NLDO probing after 1 year age. Ophthalmology. 1998; 105(7) : 1307-1310.

4. Baker J D. Treatment of CNL system obstruction. Journal of paediatric ophthalmology. 1985; 22: 34. 